\title{
Bacterial invasion across the human skin barrier - mechanisms and ensuing tissue
} degradation.

\author{
Zachary W. Lipsky ${ }^{\mathrm{a}, \mathrm{c}}$, Marisa Patsy ${ }^{\mathrm{d}}$, Cláudia N. H. Marques ${ }^{\mathrm{b}, \mathrm{c}}$,
}

\author{
${ }^{a}$ Department of Biomedical Engineering, Binghamton University, 4400 Vestal Parkway East, \\ Binghamton, NY 13902. \\ ${ }^{\mathrm{b}}$ Department of Biological Sciences, Binghamton University, 4400 Vestal Parkway East, Binghamton, \\ NY 13902. \\ ${ }^{\mathrm{c}}$ Binghamton Biofilm Research Center, Binghamton University, 4400 Vestal Parkway East, Binghamton, \\ NY 13902. \\ ${ }^{\mathrm{d}}$ Fischell Department of Bioengineering, University of Maryland, 3102 A. James Clark Hall, College \\ Park, MD 20742 \\ ${ }^{1}$ Corresponding author: Guy K. German, Binghamton University, Department of Biomedical \\ Engineering, BI2609, 4400 Vestal Parkway East, Binghamton, NY 13902, Phone (607) 777-4270, Email: \\ ggerman@binghamton.edu
}

Running Title: Mechanisms and implications of bacterial skin invasion

Keywords: Stratum Corneum, Staphylococcus aureus, Lipids, Mechanics

Abbreviations: Atopic Dermatitis (AD), Stratum corneum (SC), Ethylene-vinyl acetate (EVA), Relative humidity (RH), Scanning electron microscopy (SEM), Clumping factor B (ClfB), Fibronectin binding protein B (FnBPB), Natural moisturizing factors (NMFs), Urocanic acid (UCA), Pyrrolidine carboxylic acid (PCA), Green fluorescent protein (GFP), Brain heart infusion (BHI), Deionized water (DIW), Phosphate buffered saline (PBS), and Toluidine blue and basic fuchsin (TBBF) 


\section{Abstract}

26 Atopic Dermatitis (AD) is associated with a deficiency of skin lipids, increased populations

27 of Staphylococcus aureus in the microbiome, and structural defects in the stratum corneum (SC),

28 the outermost layer of human skin. However, the pathogenesis of $\mathrm{AD}$ is ambiguous as it is

29 unclear whether observed changes are the result of $\mathrm{AD}$ or contribute to the pathogenesis of the

30 disease. Previous studies have shown that $S$. aureus is capable of permeating across isolated

31 human SC tissue when lipids are depleted to levels consistent with AD conditions. In this study,

32 we expand upon this discovery to determine the mechanisms of bacterial penetration into the SC

33 barrier. Specifically, we establish whether bacteria are permeating intercellularly, between

34 corneocytes, or employing a combination pathway of both inter- and intra-cellular travel. The

35 mechanical implications of bacterial invasion, lipid depletion, and media immersion are also

36 evaluated using a newly developed, physiologically relevant, temperature-controlled drip

37 chamber. Results reveal that $S$. aureus can be internalized by corneocytes, indicating

38 transcellular movement through the tissue during permeation, consistent with previous

39 theoretical models. S. aureus also degrades the mechanical integrity of human SC, particularly

40 when the tissue is partially depleted of lipids. These observed mechanical changes are likely the

41 cause of broken or ruptured tissue seen as exudative lesions in AD flares. This work further

42 highlights the necessity of lipids in skin microbial barrier function. 


\section{Importance}

44 Millions of people suffer from the chronic inflammatory skin disease Atopic Dermatitis (AD),

45 whose symptoms are associated with a deficiency of skin lipids that exhibit antimicrobial

46 functions, and increased populations of the opportunistic pathogen Staphylococcus aureus.

47 However, the pathogenesis of $\mathrm{AD}$ is ambiguous, and it remains unclear if these observed changes

48 are merely the result of $\mathrm{AD}$, or contribute to the pathogenesis of the disease. In this article, we

49 demonstrate the necessity of skin lipids in preventing S. aureus from penetrating the outermost

50 barrier of human skin thereby causing a degradation in tissue integrity. In terms of AD, this

51 bacterial permeation into the viable epidermis could act as an inflammatory trigger of the disease

52 and could also explain tissue fragility and lesion formation seen with AD patients. Moreover,

53 bacterial induced degradation could lead to increased pathways and further allergen intervention

54 creating chronic irritation. 


\section{INTRODUCTION}

56 Millions of children and adults suffer from atopic dermatitis (AD) $(1,2)$, a chronic inflammatory

57 skin disease. $\mathrm{AD}$ symptoms are associated with a deficiency of skin lipids (3), increased

58 populations of Staphylococcus aureus in the microbiome (4), and structural barrier defects in the

59 stratum corneum (SC) (5), the most superficial layer of human skin. However, the pathogenesis

60 of $\mathrm{AD}$ is ambiguous, and it is unclear if these observed changes are the result of $\mathrm{AD}$ or

61 contribute to the pathology of the disease (6). We hypothesize that decreases in SC lipid

62 populations may cause sufficient barrier dysfunction to enable $S$. aureus to permeate across the

63 epidermis, and act as a potential inflammatory trigger of the disease. This could explain the

64 subset of cases that do not fit a genetically motivated disease development, either with mutations

65 in immune associated genes (IL4, IL13, RANTES, CD14, NOD1) (7, 8) or barrier function

66 associated genes (FLG) $(7,9,10)$. Our previous work has shown that $S$. aureus is capable of

67 permeating across isolated human SC tissue when lipid populations decrease to levels consistent

68 with $\mathrm{AD}$ conditions (11). As an extension of this work, we aim to utilize a newly developed

69 physiologically relevant temperature- and moisture- controlled drip chamber to investigate the

70 pathways that allow S. aureus to permeate across the tissue and the mechanical and structural

71 implications of bacterial invasion.

\section{RESULTS}

73 Lipid depletion allows permeation of $S$. aureus through the SC and internalization into

74 corneocytes.

75 The ability of $S$. aureus to penetrate isolated healthy unaltered control and lipid depleted

76 (Delipid) human SC is first assessed. Three-dimensional bacterial penetration depths within SC 
samples were characterized over a 5-day period. Fig. 1 shows representative composite fluorescent profile cross sections through the SC, with $S$. aureus shown in green and free fatty acids within the SC shown in red. Figs. $1 \mathrm{~A}$ and B show the position of bacteria on day 0,2 hours after inoculation for control and lipid depleted SC samples respectively. Figs. 1C and D show bacterial positions on day 4 for the same respective samples. Fig. 1D shows that bacteria can permeate into the lipid depleted SC, while Fig. 1C shows that bacteria on control SC do not, consistent with prior studies(11).

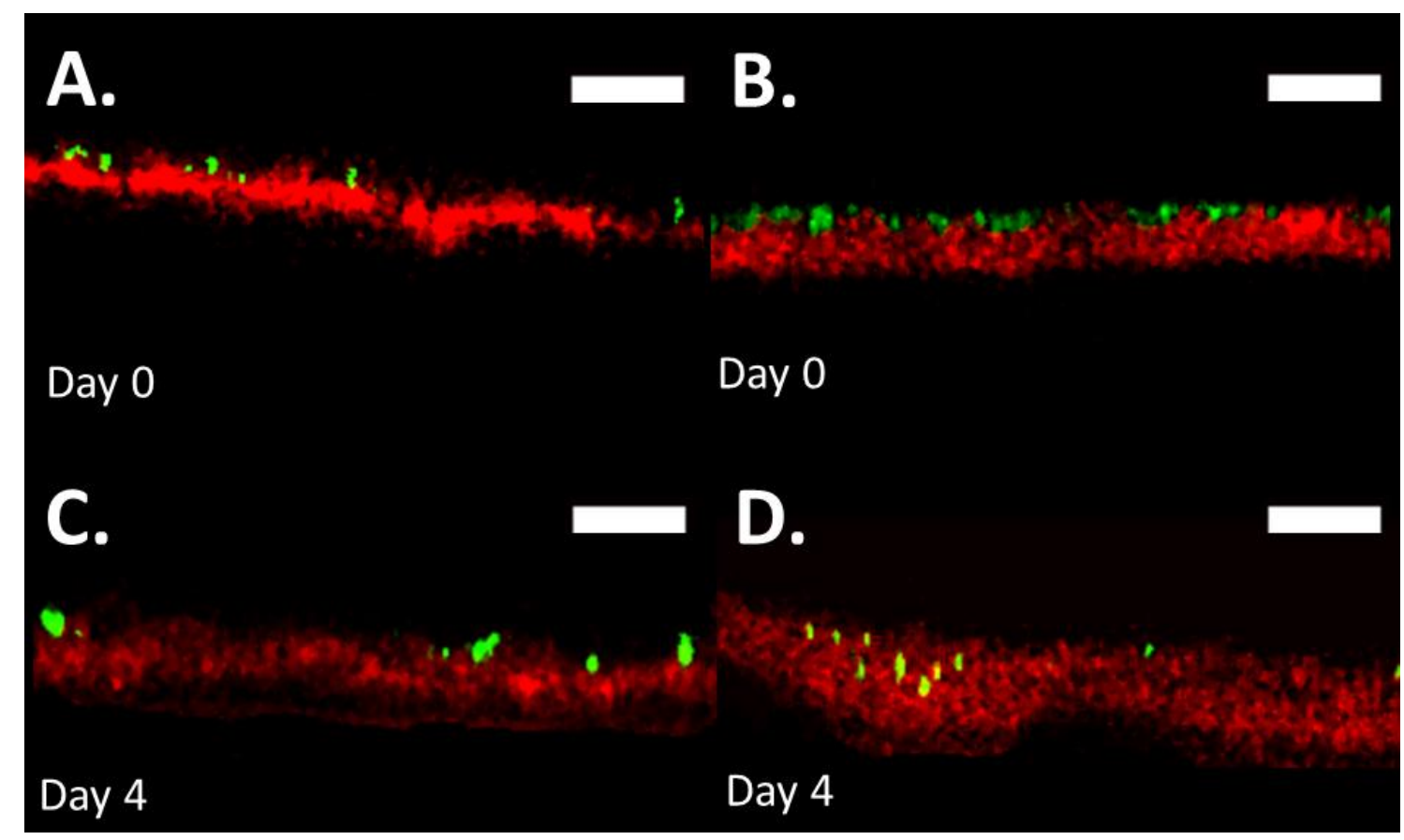

Figure 1. S. aureus penetrates lipid depleted SC in drip chamber setup. Fluorescent confocal cross-sectional profiles of $S$. aureus permeation into a control (A \& C) and delipidated (B \& D) $\mathrm{SC}$ sample over a 5-day period. Images show representative fluorescent cross-sectional profiles of BODIPY lipid stained SC (red) inoculated with GFP labeled S. aureus bacteria (green) after (A \& B) 0 , and $(\mathrm{C} \&$ D) 4 days. An identical contrast change has been imposed on all images in each lipid condition to enhance visual clarity. Scale bar $-15 \mu \mathrm{m}$.

The interactions between bacteria and the delipidated SC tissue microstructures are further investigated to better understand the permeation pathways. Previous reported models of permeation highlight that purely intercellular permeation pathways are unlikely compared with 
combined inter- and intra-cellular permeation, due to permeation timescales being notably larger than those observed (11). Permeation of these non-motile bacteria is modeled as a 3D random walk process, where the position of a new bacteria formed through binary fission is located arbitrarily next to the parent cell. For a combined inter- and intra-cellular permeation pathway to be viable however, $S$. aureus must utilize a direct transcellular route through corneocytes. Internalization of $S$. aureus has previously been shown to occur both in vivo and in vitro within keratinocytes at various levels of differentiation up until the stratum granulosum (12, 13). However, internalization in anucleated corneocytes that exhibit a cornified envelope $(14,15)$ has not previously been observed. As such, bacterial internalization assays are next performed using methods described in Kintarak et al.(16).

Fig. 2A shows the averaged ( $11 \leq n \leq 15$ independent samples for each condition) S. aureus population in CFU/mL on delipidated and control SC samples partially embedded in an ethylenevinyl acetate substrate (EVA), and EVA substrates alone. For each condition populations are quantified with and without a gentamicin treatment after a 5-day growth period. Population data is normalized and scaled to the greatest $\mathrm{CFU} / \mathrm{mL}$ magnitude per trial $(n=4)$. There are no significant differences between conditions without the addition of gentamicin, except between EVA alone and control SC. As such, bacterial populations here are not statistically affected by SC lipid concentration over the 5-day timescale. As expected, bacterial population viability reduces when treated with gentamicin. Fig. 2B shows a rescaled bar chart from Fig. 2A. For gentamicin treated conditions, the reduction of bacterial population is significantly smaller in delipidated SC tissue samples, while no statistical difference exists between gentamicin treated EVA substrates and control SC samples. 


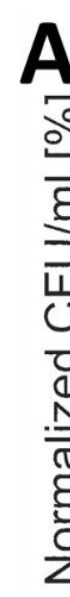

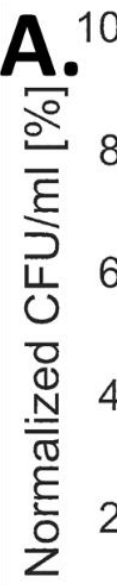

0

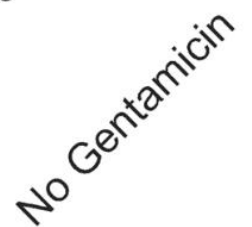

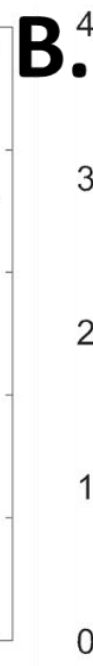

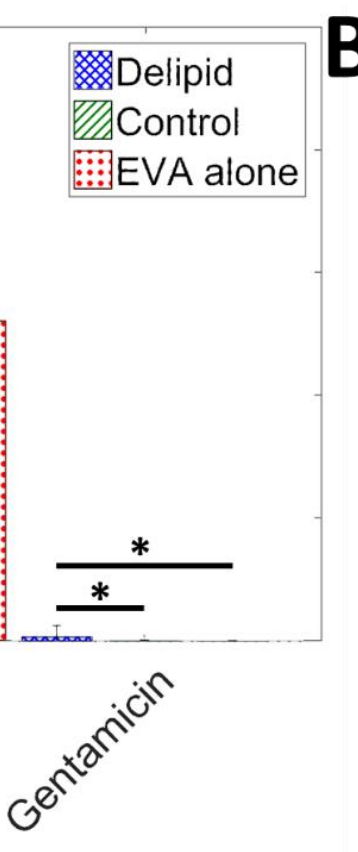

G

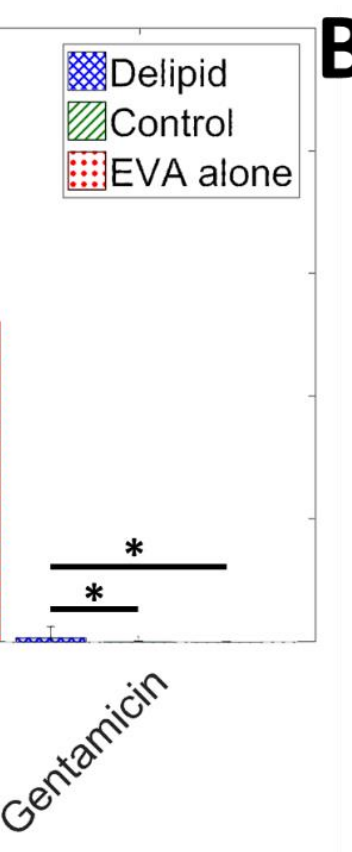

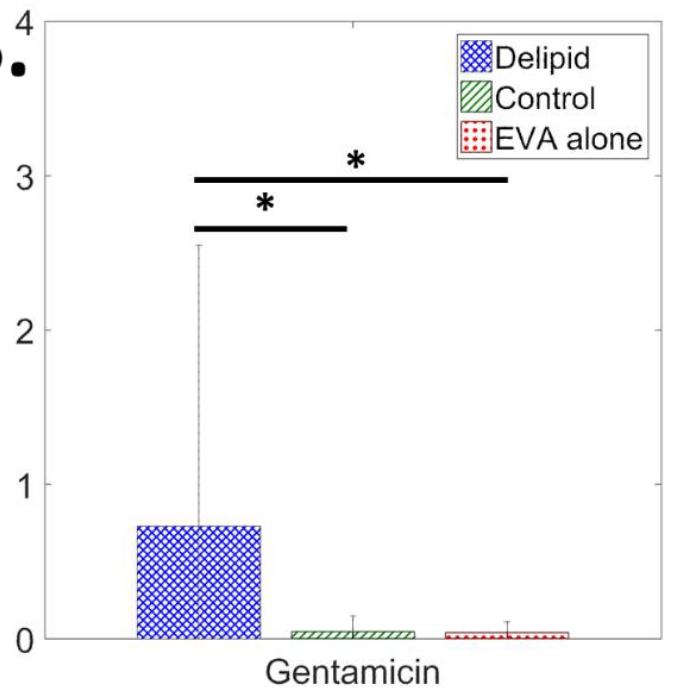

Figure 2. S. aureus is internalized by corneocytes in lipid depleted SC. (A) Average normalized bacterial population in CFU/mL, from $n=4$ independent trials, scaled by the highest $\mathrm{CFU} / \mathrm{mL}$ per trial, for delipidated SC (blue crosshatch), control SC (green stripes), and EVA alone (red dots), with and without the addition of gentamicin $(11<n<15$ for each condition). (B) Averaged normalized CFU/mL rescaled for gentamicin effected conditions only.

\section{$\underline{\text { S. aureus alters SC mechanical properties }}$}

We further examine the effect that $S$. aureus colonization, growth, permeation, and cellular internalization has on the mechanical properties of control and delipidated SC. To assess the independent effects of media immersion and bacterial colonization and permeation, SC samples are exposed to either $S$. aureus and media combined, or media alone. These are then compared with unexposed controls. For each condition, all SC samples are either equilibrated for 24 hr to 25 or $100 \%$ relative humidity $(\mathrm{RH})$ prior to uniaxial testing to examine the impact of the exposure to the linear elastic and plastic regimes of the tissue. The isolated effect of lipid depletion is further established by comparing control and delipidated SC mechanical properties 
133 without exposure to media, while the isolated effect of media immersion is determined for each

134 lipid condition by comparing SC exposed to media with non-immersed counterparts.

135 Fig. 3 shows the average elastic modulus, $E$, fracture stress, $\sigma_{f}$, fracture strain, $\gamma_{f}$, and work of 136 fracture, $W_{f}$ of control and delipidated SC subjected to the various treatment conditions, then 137 equilibrated to $25 \% \mathrm{RH}$. Fig. 3A shows that the elastic modulus increases only resulting from 138 lipid depletion, consistent with previous studies(17). Neither media immersion nor bacterial 139 growth alter the stiffness of the tissue. Figs. 3B-D further highlight that at low humidity 140 conditions, neither lipid depletion, media immersion, nor bacteria have a significant effect on the 141 fracture stress, fracture strain, or work of fracture.

142 Fig. 4 shows complementary mechanical results for SC samples equilibrated for 24 hr to $100 \%$ $143 \mathrm{RH}$ prior to mechanical testing. This conditioning enables SC tissue to undergo plastic 144 deformation before rupture. In contrast to the $25 \% \mathrm{RH}$ results in Fig. 3A, Fig. 4A shows that the 145 elastic modulus does not change for delipidation alone, nor with media immersion of control SC. 146 However, the elastic modulus does significantly increase with media immersion of the 147 delipidated SC, and with the addition of bacteria for both lipid conditions independently. Fig. 4C 148 similarly shows that lipid depletion alone has no significant effect on the fracture strain; 149 however, the addition of bacteria for both lipid conditions independently causes a significant 150 decrease in fracture strain. Supplemental Fig. S1 shows that the addition of bacteria for both lipid 151 conditions decreases the ability of the SC to plastically deform. However, no significant effects 152 are observed with the fracture strain with media immersion for either lipid conditions. Fig. 4B 153 shows that fracture stress significantly increases only after lipid depletion and does not change 154 with media immersion or the addition of bacteria for either lipid condition. Fig. 4D highlights 

media immersion and the addition of bacteria.
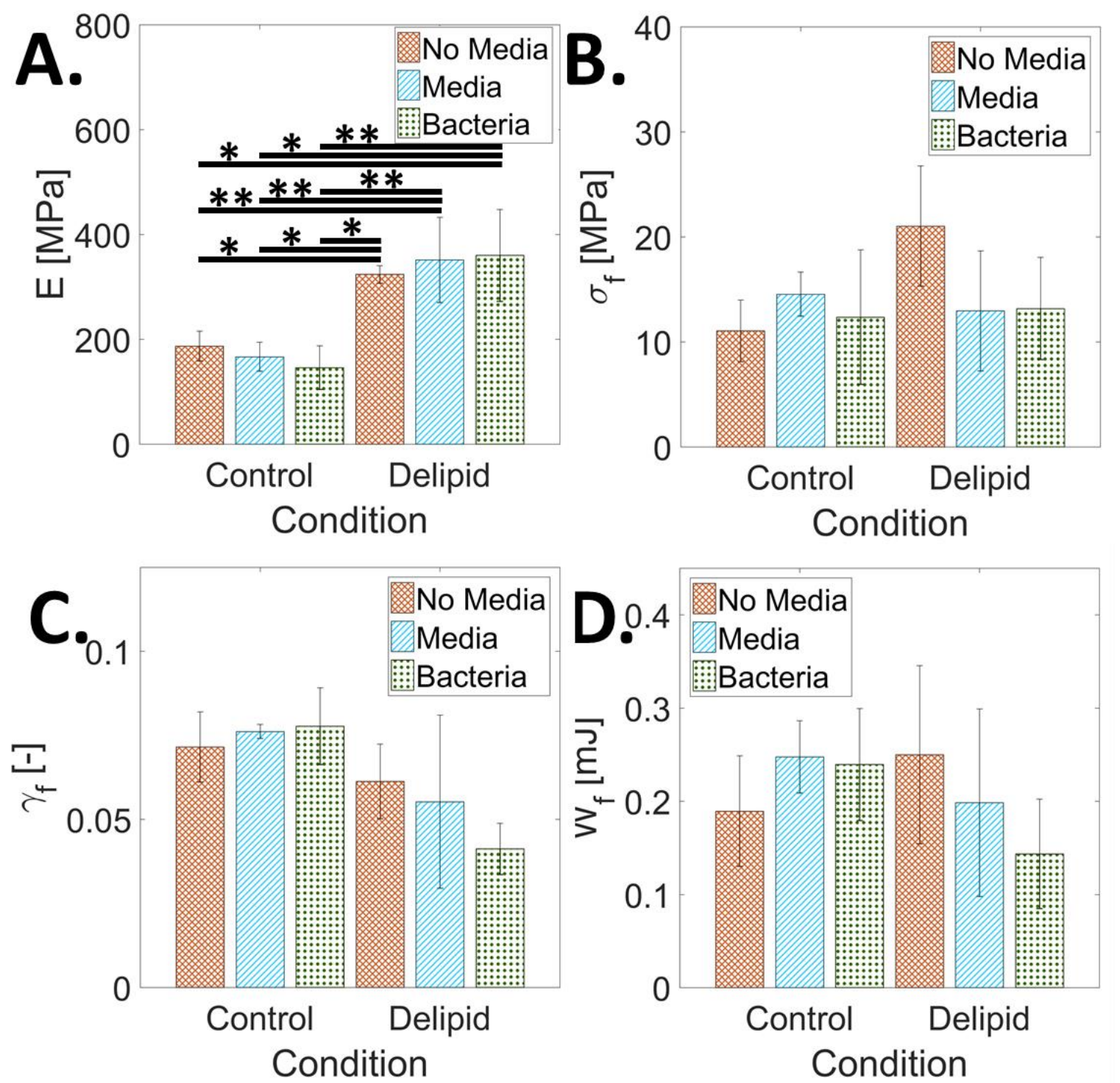

Figure 3. The effect of $S$. aureus tissue permeation, lipid loss, and media immersion on the mechanical properties of SC equilibrated to $25 \% \mathbf{R H}$. Average (A) elastic modulus, $E$, (B) fracture stress, $\sigma_{f},(\mathrm{C})$ fracture strain, $\gamma_{f}$, and (D) work of fracture, $W_{f}$, for control and delipidated SC samples. Mechanical properties of SC not immersed in media are reported with orange crosshatch bars. The effect of media immersion is reported as blue striped bars. Combined media immersion and bacterial exposure effects are reported as green dotted bars. Bars denote average values of $3 \leq n \leq 8$ individual sample measurements for each treatment condition. Error bars denote standard deviations. 


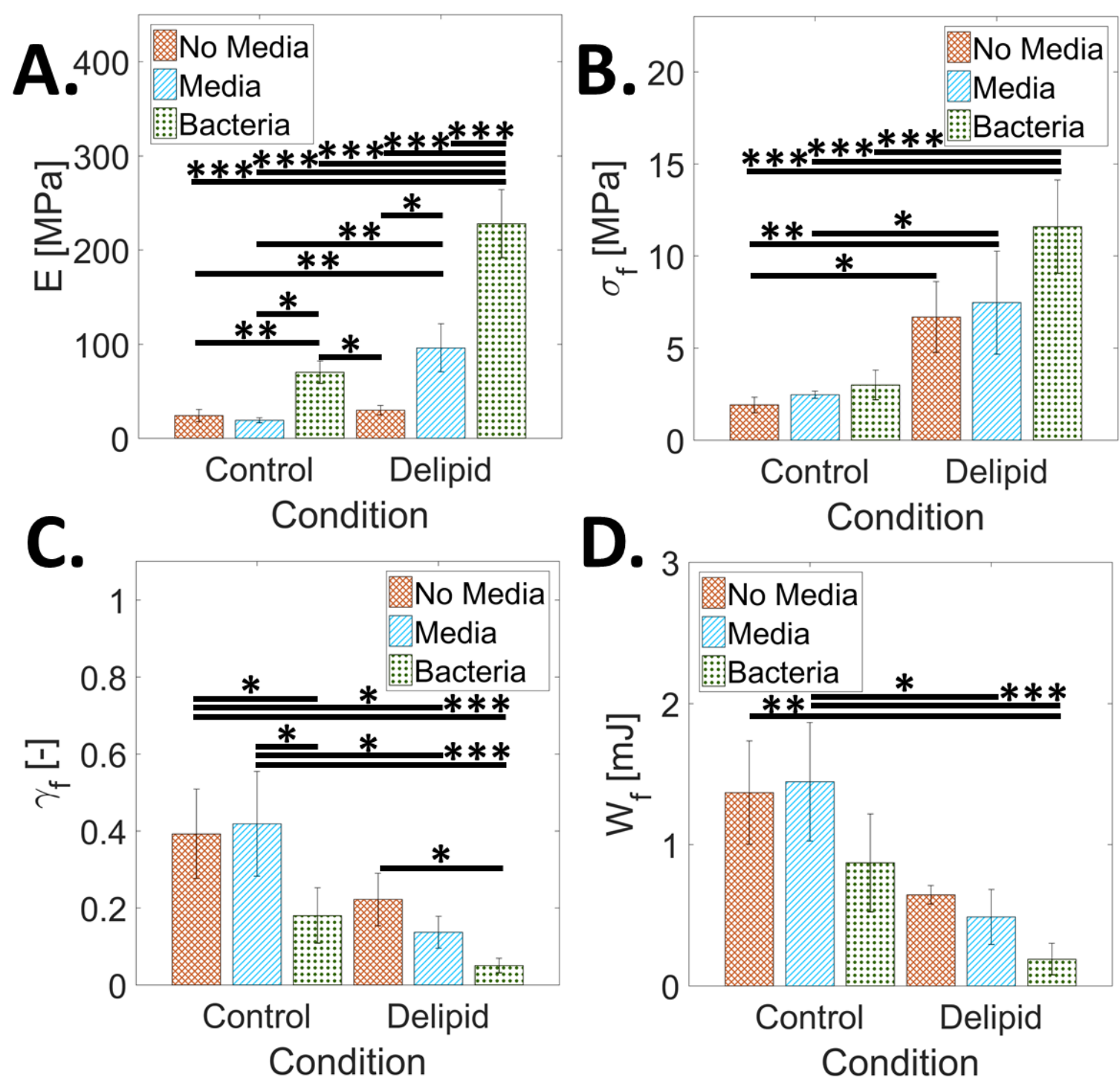

167 Figure 4. The effect of $S$. aureus tissue permeation, lipid loss, and media immersion on the 168 mechanical properties of SC at $\mathbf{1 0 0 \%}$ RH. Average (A) elastic modulus, $E$, (B) fracture stress, $\sigma_{f},(\mathrm{C})$ fracture strain, $\gamma_{f}$, and (D) work of fracture, $W_{f}$, for control and delipidated SC samples. Mechanical properties of SC not immersed in media are reported with orange crosshatch bars. The effect of media immersion is reported as blue striped bars. Combined media immersion and bacterial exposure effects are reported as green dotted bars. Bars denote average values of $3 \leq n \leq 8$ individual sample measurements for each treatment condition. Error bars denote standard deviations.

\section{Lipid content governs crack pathways during SC rupture}

177 In order to better understand how delipidation and bacterial permeation induce mechanical degradation of SC, along with what constituent components of the structurally heterogeneous 
tissue are affected at the microscale, tissue fractography studies are performed. Here, the impact of lipid depletion, media immersion, and bacterial permeation on changes to the failure pathways microcopy (SEM) are used to identify intact corneocyte cell edges along the failure pathway, as shown in Fig. 5. Similar failure pathways are observed both at low and high humidity conditions, as well as with and without immersion for each independent lipid condition. Using histological images in Fig. 5A-D, the proportion of the failure pathway coincident with corneocyte cell edges (intercellular failure) or ruptured cells (intracellular failure) is summed and normalized by the

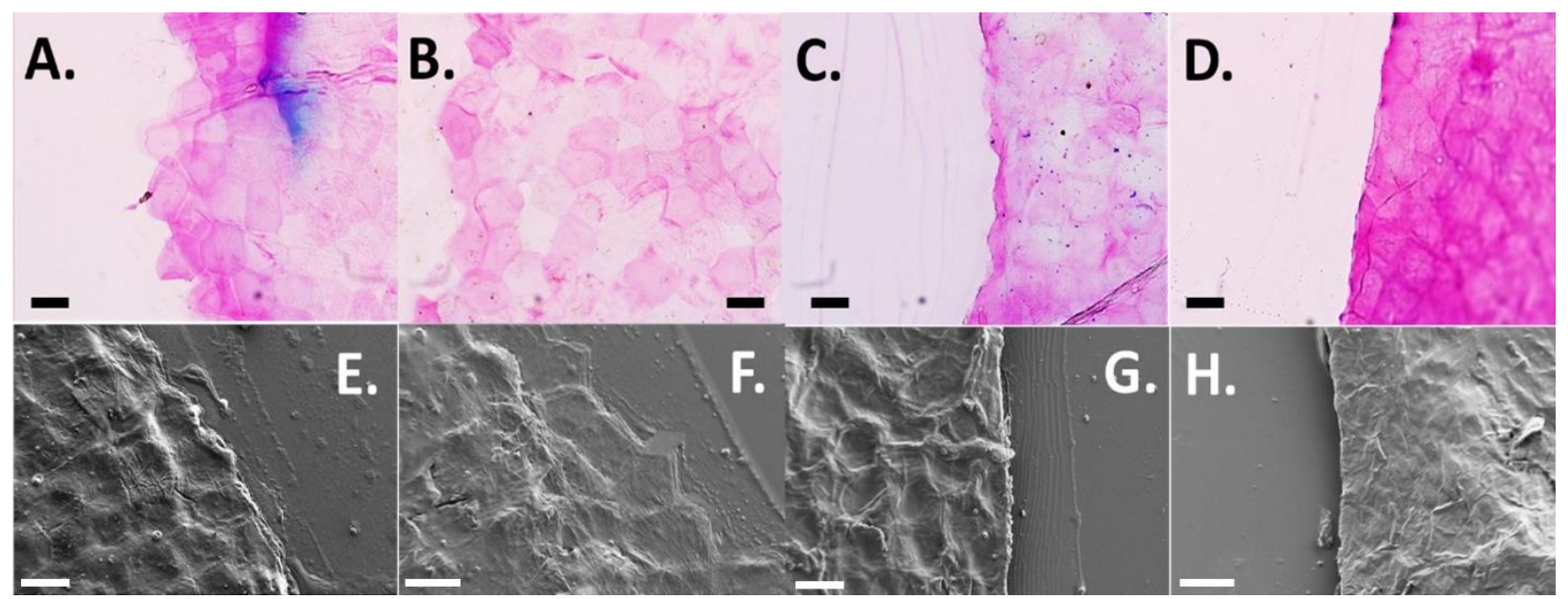
images of SC crack pathways. Scale bars - $30 \mu \mathrm{m}$. Conditions tested include control SC exposed to media only (A \& E), control SC exposed to media and bacteria (B \& F), delipidated SC exposed to media only (C \& G), and delipidated SC exposed to media and bacteria (D \& H). 


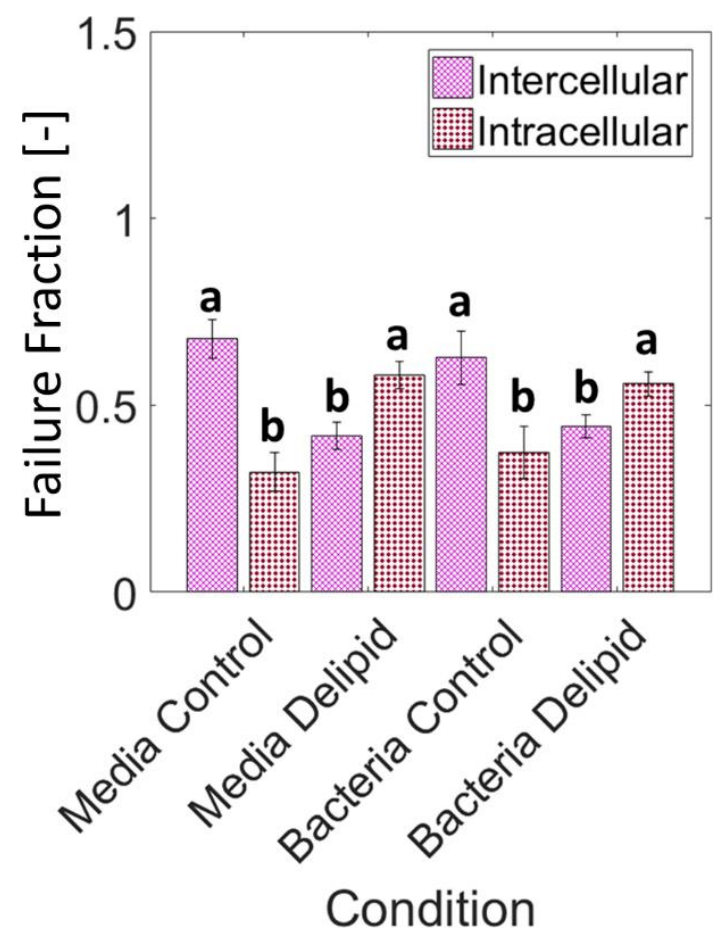

Figure 6. Intercellular and intracellular failure fraction during SC rupture. Average percentage of total inter- (purple crosshatch) and intra- (red dots) cellular failure, normalized by total SC crack length for different lipid and exposure conditions. Bars denote average values from $n=114 \pm 5$ individual corneocytes from $n=3$ SC samples for each lipid and exposure condition. Error bars denote standard deviations. "a" and " $b$ " in the figure independently denote bars that are not statistically different from one another, but are statistically different to the contrasting letter.

\section{DISCUSSION}

Previous studies have shown that $S$. aureus can permeate into and across partially delipidated $\mathrm{SC}$, with bacteria located within the tissue by day 6 of flow cell incubation at room temperature $\left(23^{\circ} \mathrm{C}\right)$ and full permeation by day $9(11)$. Using a more physiologically relevant drip chamber arrangement that more closely mimics skin temperature and diurnal hydration/dehydration cycles, we find that permeation into the tissue occurs more rapidly. Fig. 1D shows bacterial penetration into SC by day 4 . We speculate that the accelerated rate of penetration is related to the increased temperature $\left(23\right.$ to $33^{\circ} \mathrm{C}$ ), which more accurately represents average skin surface temperature $(18,19)$. The lack of inversion used in the flow cell setup may also increase 
215 permeation rates, due to increased initial bacterial sedimentation on the skin. Further, the

216 bacterial presence within corneocytes only under delipidated SC conditions confirms bacterial

217 permeation via intra and intercellular pathways, further supporting a previously published

218 diffusion model (11) that predicts bacteria are more likely to take a direct transcellular

219 permeation route rather than a purely intercellular pathway. Previous literature has reported the

220 internalization of S. aureus into other non-professional phagocytes including osteoblasts (20-22),

221 keratinocytes $(16,23,24)$, and endothelial cells (25-27). The results of Fig. 2 indicate that

222 bacterial internalization does occur with corneocytes, but only when the tissue is partially

223 delipidated.

224 We additionally investigate the effects that bacterial colonization, penetration, and bacterial 225 internalization have on the mechanical properties of the SC under control and partially lipid 226 depleted conditions. At high RH, delipidation alone only increases the fracture stress. However, 227 for both lipid conditions we observe an increase in tissue elastic modulus and a decrease in the 228 ability to plastically deform with bacterial exposure (Fig. 4A and C respectively). In-turn, this 229 degrades the mechanical integrity of the tissue (Fig. 4 D). A similar trend occurs with a reduction 230 in SC water content (28-32). Previous studies report changes in the water holding capacity of SC 231 with extracellular lipid (33) and NMF depletion (34). So while changes in the water holding 232 capacity would explain changes in the elastic modulus of tissue due to delipidation (Fig. 3A), 233 additional bacterial permeation may consequently also be affecting the presence of extracellular 234 lipids (35-40) and NMFs (41-44), that will impact the water retention ability of the tissue, 235 potentially caused by disruption of the cornified envelope during bacterial invasion into the 236 corneocyte cells. Comparing the effect of bacteria permeation, immersion and delipidation on the 237 elastic modulus of the SC at low RH conditions in Fig. 3A, we observe that only lipid depletion 
238 (45-49) causes a significant change in the elastic modulus of the tissue. Neither media 239 immersion, associated with a loss of NMFs $(40,44,50-52)$, nor bacterial presence impact tissue 240 stiffness for either lipid condition.

241 In addition to investigating the mechanical properties of SC tissue, the impact of lipid depletion, 242 media immersion, and bacterial growth on changes to the microstructural mechanical integrity 243 are also quantified. When observing fracture path in control and delipidated SC tissue (Fig. 5), cracking occurs intercellularly for the control conditions, yet intracellularly for the delipidated 245 conditions, irrespective of media immersion or bacteria growth (Fig. 6). We anticipate this lipid 246 depletion induced change occurs due to the formation of strong interactions between adjacent 247 lipid envelopes in intercellular regions of SC (53), resulting in an energetically less favorable 248 failure between corneocytes and a preference for rupture of the keratin intermediate filament 249 network within corneocytes, observable in Fig. 4B. shown to alter stratum corneum lipids directly. Nonetheless, the impact of bacterial growth and permeation on skin shows changes in the mechanical properties of SC consistent with lipid depletion; a stiffening and weakening of the tissue. This seems therefore to suggest that the 254 bacteria may potentially be altering other components of the tissue. The most likely alternative is that bacteria are affecting NMFs, either directly through enzyme degradation or indirectly by

256 NMF leaching out of the cornified envelope during cellular internalization. Certainly the most 257 prominent NMFs: Urocanic acid (UCA) (55), Ser (56), Pyrrolidine carboxylic acid (PCA) (57), 258 Glycerol (58), and Urea (59) have all been shown to be affected directly by S. aureus. To 259 ascertain the cause of bacterial medicated tissue degradation, NMF levels in SC tissue inoculated with bacteria should be compared with unexposed controls, for both normal and lipid depleted 
261 conditions, possibly using HPLC (60). It should be noted that while keratin filaments have been

262 hypothesized to plasticize with the addition of water at high $\mathrm{RH}$, contributing to SC viscoelastic

263 properties $(28,61,62)$, there have been no studies, to our knowledge, looking into the isolated

264 mechanical effect of keratin modification in SC or the effect S. aureus has on keratin in skin

265 corneocytes. These assessments should also be investigated in future studies.

\section{CONCLUSION}

267 In this article we show that Staphylococcus aureus is internalized by corneocytes in lipid 268 depleted human stratum corneum during permeation, indicating a viable transcellular route

269 through the tissue. We also show the effects that changes in lipid composition, immersion, and

270 bacterial growth into and across stratum corneum have on the mechanical deterioration of the

271 tissue. Bacterial growth acts to weaken the tissue and make it more brittle, increasing the risk of

272 tissue rupture. Skin suffering from atopic dermatitis is associated with depleted levels of

273 lipids(63) and increased populations of $S$. aureus bacteria in the microbiome(64, 65). Lipid

274 depletion and bacterial mediated mechanical degradation of the tissue could further explain the

275 formation of exudative lesions associated with atopic dermatitis. These regions of ruptured tissue

276 will lead to further entry of bacteria and other allergens into the viable epidermis, contributing to

277 a chronic state of the disease. In addition, this work shows the necessity of lipids in not only

278 preventing bacterial entry into the skin, but also governing stratum corneum mechanical barrier

279 integrity and fracture behavior. This is especially important for people that might be prone to

280 lipid depletion through abnormalities in lipid-processing proteins (66), occupational hazards such

281 as repeated hand washing required for sterile environments $(67,68)$, or contact with metal

282 working fluids, solvents and caustic chemicals (69). Lastly the connection between bacteria and 
283 immersion (natural moisturizing factors) could contribute to a lack of natural moisturizing

284 factors observed in the stratum corneum of atopic dermatitis patients $(70,71)$.

285 MATERIALS AND METHODS

286 Bacterial strains

287 All bacterial studies used Staphylococcus aureus ATCC 6538 (Rosenbach, American Type

288 Culture Collection (ATCC), Manassas, VA) isolated from human lesions. This strain was 289 modified with $p A L C 2084$ and edited to constitutively express green fluorescence protein (GFP).

290 Overnight cultures were grown in brain heart infusion medium (BHI, Becton, Dickinson, Sparks, 291 MD) supplemented with $10 \mathrm{mg} / \mathrm{L}$ chloramphenicol (Mediatech, Corning Life Sciences, Corning, $292 \mathrm{NY}$ )) for plasmid maintenance, and $250 \mathrm{ng} / \mathrm{mL}$ tetracycline (Amresco, Solon, OH) for induction 293 of GFP, in Erlenmeyer flasks at $37^{\circ} \mathrm{C}$ with agitation $(220 \mathrm{rpm})$.

\section{Stratum Corneum isolation}

295 A full thickness (76 yrs.) female cadaveric abdominal skin sample was obtained from 296 ConnectLife (Syracuse, NY). In accordance to the Department of Health and Human Services 297 regulations, 45 CFR 46.101:b:4, an exempt approval (3002-13) was attained to perform research 298 using de-identified tissue samples. SC was isolated using standard heat bath and trypsin 299 techniques (72). After isolation, SC sheets were placed on plastic mesh, rinsed in deionized 300 water (DIW), and dried at room temperature and $\mathrm{RH}\left(23 \pm 2{ }^{\circ} \mathrm{C}, 29 \pm 3 \% \mathrm{RH}\right)$.

\section{$301 \quad$ Stratum Corneum lipid depletion}

302 SC sheets were divided equally into two groups: 1. a control group immersed in DIW for 60 min 303 - this treatment does not deplete lipids or irreversibly alter the intercellular lipid structure (73), 
and 2. a treatment group, immersed in a 2:1 mixture of chloroform and methanol (Sigma-

Aldrich, St. Louis, MO) for 60 min, partially depleting intercellular ceramides, cholesterol, and

free fatty acids found in SC from the tissue (49). From estimates of human SC lipid

307 concentrations and composition $(46,74,75)$, treatments using similar solvent extraction

308 protocols on human and porcine SC (45-48) reduce lipids by $54 \pm 30 \%$. SC samples were then

309 punched out from both control and lipid-depleted (Delipid) SC tissue sheets with either a circular

$3106 \mathrm{~mm}$ diameter punch (Harris Uni-Core, Redding, CA) for the internalization assay $(n=30$

311 control $n=30$ delipid) or a rectangular 9.53 x $19.05 \mathrm{~mm}$ punch (SYNEO, Angleton, TX) for

312 mechanical testing ( $n=26$ control; $n=26$ delipid).

\section{Substrate preparation for mechanical testing}

314 A $20 \% \mathrm{w} / \mathrm{v}$ ethylene-vinyl acetate (EVA) in toluene was prepared and spin coated (WS-400B6NNP/LITE, Laurell Technologies Corporation, North Wales, PA) on to a glass coverslip (25 x toluene for $12 \mathrm{hr}$, this produced a uniform EVA film with a thickness of $91 \pm 17 \mu \mathrm{m}$. EVA substrates were then placed on a hotplate (10027-028,VWR, Radnor, PA) at $60{ }^{\circ} \mathrm{C}$ to allow the

319 EVA to soften for SC sample attachment. This temperature has shown not to create irreversible changes to the structural properties of SC(76). Control and delipidated SC samples were then

321 alternately embedded along the long axis of the cover slip $(n=6$ samples arranged in a $3 \times 2$

322 grid on each substrate) leaving only their outermost face exposed. This embedding process

323 occludes the sides and underside of the SC sample, preventing bacterial growth in these regions.

324 For each substrate tested, the order of the conditioned SC samples deposited was randomized.

325 Substrates were then degassed in a vacuum desiccator (5310-0250, Nalgene®, ThermoFisher 
Scientific, Waltham, MA) with attached vacuum pump (ME4 NT Vacuubrand, BrandTech, Essex, CT) for $4 \mathrm{hr}$. This process eliminated microbubbles between the SC and EVA.

\section{Drip chamber setup and inoculation}

Embedded SC substrates were sterilized under germicidal ultraviolet light $(254 \mathrm{~nm})$ for $15 \mathrm{~min}$, then mounted in the custom-built drip chamber (supplemental Fig. S2). This UV treatment does not alter the mechanical properties of the tissue(77). The drip chamber is an aluminum hollow block $(10 \times 112 \times 34 \mathrm{~mm})$ that has eight samarium-cobalt magnets (M14X116DISmCo, Apex Magnets, Petersburg, WV) at each corner of the underside and top. Substrates with embedded SC samples were sandwiched between the bottom steel plate and the block's magnets, holding the substrate in place magnetically. Vacuum grease (Dow Corning, Midland, Michigan) was also applied around the edges of the substrate to ensure the drip chamber was fully sealed. The upper steel plate holds another glass cover slip in place magnetically. This upper plate and cover slip could be slid backwards to allow for the addition of medium over the SC surface. The shorter sides of the block have threaded holes for a brass inlet (5454K62, McMaster-Carr, Chicago, IL) and outlet. The brass inlet was connected to a gas permeable filter (200 nm pore size) via silicone tubing (96400-14, Cole-Parmer, Vernon Hills , IL) to maintain atmospheric pressure. The brass outlet was connected to a cross connector (5463K93, McMaster-Carr, Chicago, IL) via silicone tubing. The cross connector separates the injection ports for the fatty acid dye (D3835, ThermoFisher Scientific, Waltham, MA) and bacterial inoculum, and an outlet port for waste. Each port on the cross connecter was connected to a Luer lock coupling (51525K322, McMaster-

Carr, Chicago, IL) via silicone tubing. The drip chamber was first injected with $5 \mathrm{~mL}$ fatty acid dye at a $10 \mu \mathrm{M}$ concentration in $10 \% \mathrm{BHI}$ medium (Franklin Lakes, NJ). The lipid stain was 
allowed to bind to all SC samples for $30 \mathrm{~min}$. To remove unbound dye from the chamber, $15 \mathrm{~mL}$ phosphate buffered saline (PBS) was injected into the chamber, then decanted out of the outlet port. The fluorescent fatty acid stain was found not to alter the growth behavior of the bacteria.

352 Following staining, the chamber was injected with $5 \mathrm{~mL}$ of a stationary phase culture of $S$. aureus $\left(10^{8} \mathrm{CFU} / \mathrm{mL}\right)$. The bacteria were allowed to attach to the SC surface for $2 \mathrm{hr}$. Unattached bacteria were washed away with $15 \mathrm{~mL}$ of PBS, injected into the chamber and then decanted. The top of the drip chamber was then slid backwards and 2 drops (50 $\mu 1 /$ drop) of $20 \%$ BHI medium, supplemented with $250 \mathrm{ng} / \mathrm{mL}$ tetracycline for induction of GFP, was added to each SC sample to maintain hydration and bacterial growth. The top was then slide back into place, and the chamber was placed on a hotplate (10027-028,VWR, Radnor, PA) to simulate average skin surface temperature at $33{ }^{\circ} \mathrm{C}(18,19)$. Media was added to the chamber each day for 5 days total until sterilization and removal of the SC from the substrate for mechanical testing. The setup was kept in a biosafety level 2 hood (Class II Type A2, Labconco, Kansas City, MO), except for imaging.

\section{Microscopic imaging of bacterial colonization of SC}

S. aureus growth was monitored every $24 \mathrm{hr}$ using confocal laser scanning microscopy (Leica

367 SC samples were illuminated sequentially with transmitted light, then at 455 and $543 \mathrm{~nm}$. Images

368 for the latter two excitation wavelengths were captured respectively across a bandwidth of 500-

369540 and 560-590 $\mathrm{nm}$. Transmitted light images were used to distinguish topographical regions of 
372 arising from apocrine pores(11). The $455 \mathrm{~nm}$ illumination was used to excite GFP-tagged $S$.

373 aureus. The $543 \mathrm{~nm}$ illumination was used to excite the fluorescent BODIPY stained SC. At

374 each recorded time point, z-stack images were taken across the full depth of the SC sample and

375 substrate at height increments of $0.15 \mu \mathrm{m}$.

\section{$376 \quad$ Internalization assay}

377 Individual wells in 24-well plates $(n=4$ plates total) were coated with $200 \mu 1$ of $20 \%$ EVA

378 polymer dissolved in toluene. The solvent was then allowed to evaporate for $12 \mathrm{hr}$. Control

$379(n=8)$ and delipid $(n=8)$ SC samples were then independently embedded in each well leaving

380 only their outermost face exposed. Wells containing EVA alone $(n=8)$ were used as tissue free

381 controls. Each 24-well plate was then degassed in a vacuum desiccator for $4 \mathrm{hr}$ to eliminate

382 microbubbles between the SC and EVA. The well plates were then sterilized under ultraviolet

383 light for $15 \mathrm{~min}$. Following this, each well was filled with $300 \mu$ l stationary phase culture of $S$.

384 aureus $\left(10^{8} \mathrm{CFU} / \mathrm{mL}\right)$. The bacteria were allowed to attach to the SC surface or EVA polymer

385 alone for $2 \mathrm{hr}$. Unattached bacteria were washed away with three rinses of PBS. Each day

386 thereafter, for 5 days, 2 drops (50 $\mu \mathrm{l} / \mathrm{drop})$ of $20 \%$ BHI medium, supplemented with $250 \mathrm{ng} / \mathrm{mL}$

387 tetracycline, were added to each well to maintain hydration and bacterial growth. Plates were

388 then placed on a hotplate at $33^{\circ} \mathrm{C}$. On the $5^{\text {th }}$ day, methods described in Kintarak et al were used

389 (16). Half of the wells in each condition (Control; Delipidated; EVA alone) were exposed to a 1

$390 \mathrm{~mL}$ solution of $100 \mu \mathrm{g} / \mathrm{mL}$ of gentamicin, killing extracellular bacteria. The plate was then

391 incubated for $2 \mathrm{hr}$ at $37^{\circ} \mathrm{C}$ and rinsed twice with PBS. Each well was then filled with $1 \mathrm{~mL} 0.5 \%$

392 Triton X-100 (Sigma-Aldrich, St. Louis, MO). Wells containing SC were macerated with a

393 pipette tip. To determine internalized bacterial viable counts, serial dilutions of each well were 
plated on 2:1 plate count agar (247930, BD, Franklin Lakes, NJ) to standard agar (214530, BD, Franklin Lakes, NJ).

\section{$\underline{\text { SC sterilization, removal, and mechanical testing }}$}

After 5 days of bacterial colonization and subsequent permeation, substrates were sterilized with 
417 quantified with optical microscopy using an Eclipse Ti-U inverted microscope (Nikon, Melville,

418 NY) with 40X oil objective lens (Nikon Plan UW, Nikon, Melville, NY). Images were recorded

419 using a digital CCD camera (Andor Clara, Belfast, Northern Ireland). Optical thickness

420 measurements were taken a distance from the crack interface to prevent measuring reduced

421 thicknesses arising from plastic deformation. Combinations of sample dimensions, and recorded

422 force-displacement data were then used to derive engineering stress-strain curves, from which

423 the average elastic modulus, fracture stress, fracture strain and work of fracture were extracted.

424 SC subjected to the same protocol without the addition of bacteria was used as media controls for

425 each lipid condition.

\section{SC failure pathway imaging and failure method calculation}

427 After mechanical testing, fractured SC sample pieces were subjected to either SEM $(n=3$

428 sample halves per condition), or histological staining and widefield transmission microscopy

429 ( $n=3$ sample halves per condition) to determine the proportion of inter- and intra-cellular crack

430 pathways. For SEM imaging, fractured halves were laminated onto square glass coverslips (22

431 X22X-2, Thermofisher Scientific, Waltham, MA) and adhered to SEM pin mounts (16144, TED

432 PELLA, Redding, CA) using carbon tape (16084-3, TED PELLA, Redding, CA). To increase

433 conduction, copper tape (102091-345, VWR, Radnor, PA) was used to create a path from the

434 bottom of the chuck to the fractured SC sample. The SEM substrate was then sputtered using a

435 carbon coater (208C High Vacuum Turbo Carbon Coater, Cressington). SC failure pathways

436 were then imaged on an SEM (ZEISS FEG- SEM Supra 55 VP) with a voltage of 0.7-1.5 kV.

437 For histological staining, fractured halves were laminated onto glass slides (16004-422, VWR,

438 Radnor, PA) and exposed to toluidine blue and basic fuchsin (TBBF) stain in $30 \%$ ethanol

439 (Delasco, Council Bluffs, IA) for $1 \mathrm{~min}$. This process dyes the intercellular regions of the SC, 
440

441

442

443

444

445

446

447

448

449

450

451

452

453

enabling visualization of individual corneocytes. Slides were then rinsed with DIW for 1 min and allowed to dry for $2 \mathrm{hr}$. A drop of mounting media (8310-16,Thermofisher Scientific, Waltham, MA) was then added to each slide before the coverslip was mounted (48393-059, VWR, Radnor, PA). Prepared slides were then imaged along the failure pathway using a light microscope (BX43, Olympus, Tokyo, Japan) and 50x objective.

Images of the SC failure pathway from the TBBF stained tissue samples were used to quantify the total fracture crack length and the proportions of both intercellular (Fig. 7A) and intracellular failure (Fig. 7B). Intercellular failure resulted with intact corneocytes with well-defined polygonal edges. Intracellular failure resulted with broken corneocytes without well-defined polygonal morphologies. Images were taken interspersed across the entire width of the SC sample $(9.53 \mathrm{~mm})$, representing $13-21 \%$ of the total crack length $(n=3$ samples per condition, $n=114 \pm 5$ corneocytes total per condition). Corneocytes with edges that were not all well distinguished were not used, as shown in Fig. 7C. The total lengths of intercellular and intracellular failure normalized by the total crack length measured provide the proportion of intercellular to intracellular failure for each condition.

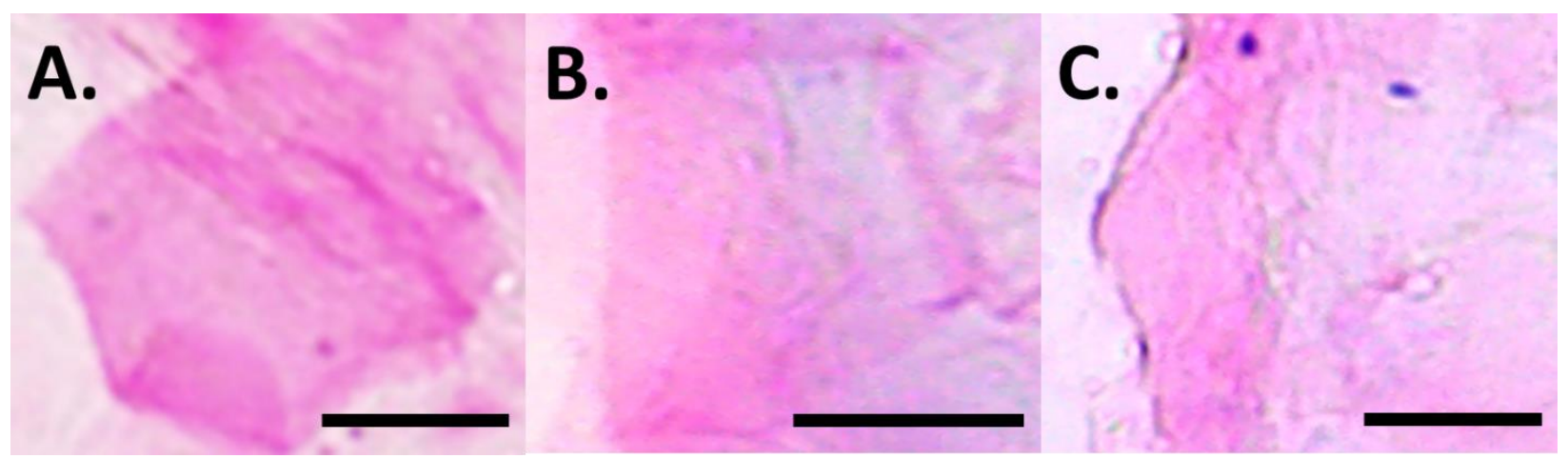

Figure 7. Corneocyte integrity along SC failure pathway. Examples of TBBF stained (A) intact, (B) broken, and (C) indistinguishable corneocytes imaged at 50x along a fractured SC pathway. Scale bar - $15 \mu \mathrm{m}$. 


\section{$\underline{\text { Statistical analysis }}$}

461 All statistical analyses were performed using R (version 3.4.2). A 1-way ANOVA was used to

462 test for statistical significance in: Fig. 2, where the addition or lack of gentamicin was compared 463 independently across all sample types (Control, Delipid, and EVA alone), Fig. 3 and Fig. 4, 464 where comparisons were made across all lipid and exposure conditions, and Fig. 6, where 465 comparisons are made across all failure preferences, and lipid and exposure conditions. Levene's 466 and Shapiro-Wilk's tests were respectively used to determine equality of variances and 467 normality. Results in Fig. 2A and B were found to exhibit non-normal distributions and unequal 468 variance. Here a Kruskal-Wallace analysis was performed. Results in Fig. 3A and Fig. 4B and C 469 were found to exhibit normal distributions and unequal variances. Here a 1-way ANOVA with 470 Welch correction was performed. Results in Fig. 3B-D, Fig. 4A and D, and Fig. 6 were found to 471 exhibit normal distributions and equal variances. Here a standard 1-way ANOVA was 472 performed. Post-hoc analyses were performed if statistical significance levels below 5\% were 473 established. In the figures, * denotes $p \leq 0.05$, ** denotes $p \leq 0.01$, *** denotes $\mathrm{p} \leq 0.001$, 474 and matching letters denote $p \geq 0.05$.

\section{ACKNOWLEDGEMENTS}

476 This material is based upon work supported by the National Science Foundation under Grant No.

4771653071 and Grant No. 1757846. We would also like to thank Elana Chazen, Amanda Kenny, 478 and Caitlin M Begley for originally designing the drip chamber device. We would also like to 479 thank F. D. C. Willard for useful conversations about this work.

\section{COMPETING INTERESTS}

481 The authors state no conflict of interest.

\section{REFERENCES}


483 1. Barbarot S, Auziere S, Gadkari A, Girolomoni G, Puig L, Simpson EL, Margolis DJ, de Bruin-Weller M, Eckert L. 2018. Epidemiology of atopic dermatitis in adults: Results from an international survey. Allergy Eur J Allergy Clin Immunol.

2. Asher MI, Montefort S, Björkstén B, Lai CK, Strachan DP, Weiland SK, Williams H. 2006. Worldwide time trends in the prevalence of symptoms of asthma, allergic rhinoconjunctivitis, and eczema in childhood: ISAAC Phases One and Three repeat multicountry cross-sectional surveys. Lancet.

3. Imokawa GL of C in SC of ADAEF in ADS, Abe A, Jin K, Higaki Y, Kawashima M,

4. Chiller K, Selkin BA, Murakawa GJ. 2001. Skin microflora and bacterial infections of the skin. JInvestigDermatolSympProc 6:170-174.

495 5. Agrawal R, Woodfolk JA. 2014. Skin Barrier Defects in Atopic Dermatitis. Curr Allergy Asthma Rep 14:433.

497 6. Sullivan M, Silverberg NB. 2017. Current and emerging concepts in atopic dermatitis pathogenesis. Clin Dermatol.

7. Barnes KC. 2010. An update on the genetics of atopic dermatitis: Scratching the surface in 2009. J Allergy Clin Immunol.

501 8. Hanifin JM. 2009. Evolving concepts of pathogenesis in atopic dermatitis and other eczemas. J Invest Dermatol 129:320-322.

503 9. Morar N, Cookson WOCM, Harper JI, Moffatt MF. 2007. Filaggrin mutations in children with severe atopic dermatitis. J Invest Dermatol. 
Sandilands A, Campbell LE, Smith FJD, O’Regan GM, Watson RM, Cecil JE, Bale SJ, Compton JG, DiGiovanna JJ, Fleckman P, Lewis-Jones S, Arseculeratne G, Sergeant A, Munro CS, El Houate B, McElreavey K, Halkjaer LB, Bisgaard H, Mukhopadhyay S, McLean WHI. 2006. Common loss-of-function variants of the epidermal barrier protein filaggrin are a major predisposing factor for atopic dermatitis. Nat Genet 38:441-446.

11. Lipsky ZW, Marques CNH, German GK. 2020. Lipid depletion enables permeation of Staphylococcus aureus bacteria through human stratum corneum. Tissue Barriers 1754706.

12. Soong G, Paulino F, Wachtel S, Parker D, Wickersham M, Zhang D, Brown A, Lauren C, Dowd M, West E, Horst B, Planet P, Prince A. 2015. Methicillin-resistant Staphylococcus aureus adaptation to human keratinocytes. MBio.

13. Rigaill J, Morgene MF, Gavid M, Lelonge Y, He Z, Carricajo A, Grattard F, Pozzetto B, Berthelot P, Botelho-Nevers E, Verhoeven PO. 2018. Intracellular activity of antimicrobial compounds used for Staphylococcus aureus nasal decolonization. J Antimicrob Chemother.

14. Candi E, Schmidt R, Melino G. 2005. The cornified envelope: a model of cell death in the skin. Nat Rev Mol cell Biol 6:328.

15. Kalinin A, Marekov LN, Steinert PM. 2001. Assembly of the epidermal cornified cell envelope. J Cell Sci.

16. Kintarak S, Whawell SA, Speight PM, Packer S, Nair SP. 2004. Internalization of Staphylococcus aureus by human keratinocytes. Infect Immun.

17. German GKK, Pashkovski E, Dufresne ERR. 2013. Surfactant treatments influence drying mechanics in human stratum corneum. J Biomech 46:2145-2151. 
529 18. Winkel J, Jørgensen K. 1991. Significance of skin temperature changes in surface electromyography. Eur J Appl Physiol Occup Physiol.

19. Atmaca I, Yigit A. 2006. Predicting the effect of relative humidity on skin temperature and skin wettedness. J Therm Biol.

20. Van Nhieu GT, Isberg RR. 1993. Bacterial internalization mediated by $\beta 1$ chain integrins is determined by ligand affinity and receptor density. EMBO J.

535 21. Sinha B, François PP, Nüße O, Foti M, Hartford OM, Vaudaux P, Foster TJ, Lew DP, Herrmann M, Krause KH. 1999. Fibronectin-binding protein acts as Staphylococcus aureus invasin via fibronectin bridging to integrin $\alpha 5 \beta 1$. Cell Microbiol.

22. Fowler T, Wann ER, Joh D, Johansson S, Foster TJ, Höök M. 2000. Cellular invasion by Staphylococcus aureus involves a fibronectin bridge between the bacterial fibronecticbinding MSCRAMMs and host cell $\beta 1$ integrins. Eur J Cell Biol.

23. Dziewanowska K, Carson AR, Patti JM, Deobald CF, Bayles KW, Bohach GA. 2000. Integrins: Role in Internalization by Epithelial Cells. Infect Immun.

24. Hirschhausen N, Schlesier T, Schmidt MA, Götz F, Peters G, Heilmann C. 2010. A novel staphylococcal internalization mechanism involves the major autolysin Atl and heat shock cognate protein Hsc70 as host cell receptor. Cell Microbiol.

547 25. Askarian F, Uchiyama S, Valderrama JA, Ajayi C, Sollid JUE, van Sorge NM, Nizet V, van Strijp JAG, Johannessen M. 2017. Serineaspartate repeat protein D increases Staphylococcus aureus virulence and survival in blood. Infect Immun. 
reduces Staphylococcus aureus attachment to sheared human endothelial cells. J Thromb Haemost.

27. Claes J, Liesenborghs L, Peetermans M, Veloso TR, Missiakas D, Schneewind O, anchor Staphylococcus aureus to the vessel wall. J Thromb Haemost.

28. Papir Y, Hsu K, Wildnauer RH, Hsh K, Wildnauer RH, Hsu K, Wildnauer RH. 1975. The mechanical properties of stratum corneum: I. The effect of water and ambient temperature on the tensile properties of newborn rat stratum corneum. Biochim Biophys Acta (BBA)... 399:170-180.

29. Alonso a, Meirelles NC, Yushmanov VE, Tabak M. 1996. Water increases the fluidity of intercellular membranes of stratum corneum: correlation with water permeability, elastic, and electrical resistance properties. J Invest Dermatol.

30. Wildnauer RH, Bothwell JW, Douglass AB. 1971. Stratum corneum biomechanical properties I. Influence of relative humidity on normal and extracted human stratum corneum. J Invest Dermatol 56:72-78.

568 31. 2016. The global mechanical properties and multi-scale failure mechanics of heterogeneous human stratum corneum. Acta Biomater 43:78-87.

570 32. Wu KS, van Osdol WW, Dauskardt RH. 2006. Mechanical properties of human stratum corneum: effects of temperature, hydration, and chemical treatment. Biomaterials.

572 33. Imokawa G, Hattori M. 1985. A possible function of structural lipids in the water-holding 573 properties of the stratum corneum. J Invest Dermatol 84:282-284.

574 34. Visscher MO, Tolia GT, Wickett RR, Hoath SB. 2003. Effect of soaking and natural 
moisturizing factor on stratum corneum water-handling properties. J Cosmet Sci 54:289_

576

577

578

579

580

581

582

583

584

585

586

587

588

589

590

591

592

593

594

595

596

597 300.

35. Vyumvuhore R, Tfayli A, Duplan H, Delalleau A, Manfait M, Baiilet-Guffroy A. 2013. Effects of atmospheric relative humidity on Stratum Corneum structure at the molecular level: Ex vivo Raman spectroscopy analysis. Analyst.

36. Imokawa G, Kuno H, Kawai M. 1990. Stratum Corneum Lipids Serve as a Bound-Water Modulator. J Invest Dermatol 96:845-851.

37. Vyumvuhore R, Tfayli A, Biniek K, Duplan H, Delalleau A, Manfait M, Dauskardt R, Baillet-Guffroy A. 2015. The relationship between water loss, mechanical stress, and molecular structure of human stratum corneum ex vivo. J Biophotonics 8:217-225.

38. Park AC. 1972. Rheology of stratum corneum-II: A physico-chemical investigation of factors influencing the water content of the corneum. J Soc Cosmet 23:13-21.

39. Leveque JL, Escoubez M, Rasseneur L. 1987. WATER-KERATIN INTERACTION IN HUMAN STRATUM CORNEUM. Bioeng Ski 3:227-242.

40. Yamamura T, Tezuka T. 1989. The Water-Holding Capacity of the Stratum Corneum Measured by 1 H-NMR. J Invest Dermatol 93:160-164.

41. Björklund S, Andersson JM, Pham QD, Nowacka A, Topgaard D, Sparr E. 2014. Stratum corneum molecular mobility in the presence of natural moisturizers. Soft Matter 10:45354546.

42. Van Duzee BF. 1978. The influence of water content, chemical treatment and temperature on the rheological properties of stratum corneum. J Invest Dermatol 71:140-144.

43. Choe C, Schleusener J, Lademann J, Darvin ME. 2017. Keratin-water-NMF interaction as a three layer model in the human stratum corneum using in vivo confocal Raman 
microscopy $1-13$.

44. Nakagawa N, Sakai S, Matsumoto M, Yamada K, Nagano M, Yuki T, Sumida Y, Uchiwa H. 2004. Relationship between NMF (lactate and potassium) content and the physical properties of the stratum corneum in healthy subjects. J Invest Dermatol.

45. Caussin J, Gooris GS, Janssens M, Bouwstra JA. 2008. Lipid organization in human and porcine stratum corneum differs widely, while lipid mixtures with porcine ceramides model human stratum corneum lipid organization very closely. Biochim Biophys Acta (BBA)-Biomembranes 1778:1472-1482.

46. Abrams K, Harvell JD, Shriner D, Wertz P, Maibach H, Maibach HI, Rehfeld SJ. 1993. Effect of organic solvents on in vitro human skin water barrier function. J Invest Dermatol 101:609-613.

47. Lampe M a, Burlingame a L, Whitney J, Williams ML, Brown BE, Roitman E, Elias PM. 1983. Human stratum corneum lipids: characterization and regional variations. J Lipid Res 24:120-130.

48. Wertz PW, Kremer M, Squier CA. 1992. Comparison of lipids from epidermal and palatal stratum corneum. J Invest Dermatol 98:375-378.

49. Bligh EG, Dyer WJ. 1959. A rapid method of total lipid extraction and purification. Can J Biochem Physiol 37:911-917.

50. Bow JR, Sonoki Y, Uchiyama M, Shimizu E, Tanaka K, Dauskardt RH. 2020. Lipid Loss Increases Stratum Corneum Stress and Drying Rates. Skin Pharmacol Physiol.

51. Robinson M, Visscher M, Laruffa A, Wickett R. 2010. Natural moisturizing factors (NMF) in the stratum corneum (SC). I. Effects of lipid extraction and soaking. 
properties of the stratum corneum by solid-state $13 \mathrm{C}$-nuclear magnetic resonance spectroscopy. J Invest Dermatol 104:806-812.

53. Wertz PW, Swartzendruber DC, Kitko DJ, Madison KC, Downing DT. 1989. The role of the corneocyte lipid envelopes in cohesion of the stratum corneum. J Invest Dermatol.

54. Ohnishi Y, Okino N, Ito M, Imayama S. 1999. Ceramidase activity in bacterial skin flora as a possible cause of ceramide deficiency in atopic dermatitis. Clin Diagn Lab Immunol.

55. Nath S, Kumari N, Bandyopadhyay D, Sinha N, Majumder PP, Mitra R, Mukherjee S. 2020. Dysbiotic Lesional Microbiome With Filaggrin Missense Variants Associate With Atopic Dermatitis in India. Front Cell Infect Microbiol.

56. Williams MR, Nakatsuji T, Sanford JA, Vrbanac AF, Gallo RL. 2017. Staphylococcus aureus Induces Increased Serine Protease Activity in Keratinocytes. J Invest Dermatol.

57. Patti JM, Schneider A, Garza N, Boles JO. 1995. Isolation and characterization of pcp, a gene encoding a pyrrolidone carboxyl peptidase in Staphylococcus aureus. Gene.

58. Yang JJ, Chang TW, Jiang Y, Kao HJ, Chiou BH, Kao MS, Huang CM. 2018.

Commensal staphylococcus aureus provokes immunity to protect against skin infection of methicillin-resistant staphylococcus aureus. Int J Mol Sci.

59. Zhou C, Bhinderwala F, Lehman MK, Thomas VC, Chaudhari SS, Yamada KJ, Foster KW, Powers R, Kielian T, Fey PD. 2019. Urease is an essential component of the acid response network of Staphylococcus aureus and is required for a persistent murine kidney infection. PLoS Pathog.

60. Dapic I, Jakasa I, Yau NLH, Kezic S, Kammeyer A. 2013. Evaluation of an HPLC Method for the Determination of Natural Moisturizing Factors in the Human Stratum Corneum. Anal Lett. 
644

645

646

647

648

649

650

651

652

653

654

655

656

657

658

659

660

661

662

663

664

665

666

61. Takahashi M, Kawasaki K, Tanaka M, Ohta S, Tsuda Y. 1981. The mechanism of stratum corneum plasticization with water, p. 67-73. In Bioengineering and the Skin. Springer.

62. Mojumdar EH, Pham QD, Topgaard D, Sparr E. 2017. Skin hydration: Interplay between molecular dynamics, structure and water uptake in the stratum corneum. Sci Rep 7.

63. Arikawa J, Ishibashi M, Kawashima M, Takagi Y, Ichikawa Y, Imokawa G. 2002.

Decreased levels of sphingosine, a natural antimicrobial agent, may be associated with vulnerability of the stratum corneum from patients with atopic dermatitis to colonization by Staphylococcus aureus. J Invest Dermatol 119:433-9.

64. Kong HH, Oh J, Deming C, Conlan S, Grice E a., Beatson M a., Nomicos E, Polley EC, Komarow HD, Mullikin J, Thomas J, Blakesley R, Young A, Chu G, Ramsahoye C, Lovett S, Han J, Legaspi R, Sison C, Montemayor C, Gregory M, Hargrove A, Johnson T, Riebow N, Schmidt B, Novotny B, Gupta J, Benjamin B, Brooks S, Coleman H, Ho SL, Schandler K, Stantripop M, Maduro Q, Bouffard G, Dekhtyar M, Guan X, Masiello C, Maskeri B, McDowell J, Park M, Vemulapalli M, Murray PR, Turner ML, Segre J a. 2012. Temporal shifts in the skin microbiome associated with disease flares and treatment in children with atopic dermatitis. Genome Res 22:850-859.

65. Cleary JM, Lipsky ZW, Kim M, Marques CNH, German GK. 2018. Heterogeneous ceramide distributions alter spatially resolved growth of Staphylococcus aureus on human stratum corneum. J R Soc Interface 15:20170848.

66. Levin J, Friedlander SF, Del Rosso JQ. 2013. Atopic dermatitis and the stratum corneum part 2: Other structural and functional characteristics of the stratum corneum barrier in atopic skin. J Clin Aesthet Dermatol.

67. Ananthapadmanabhan KP, Moore DJ, Subramanyan K, Misra M, Meyer F. 2004. 
Cleansing without compromise: the impact of cleansers on the skin barrier and the technology of mild cleansing. Dermatol Ther 17 Suppl 1:16-25.

669

670

671

672

673

674

675

676

677

678

679

680

681

682

683

684 685

76. Van Duzee BF. 1975. Thermal analysis of human stratum corneum. J Invest Dermatol.

68. Kirk JE. 1966. Hand washing. Quantitative studies on skin lipid removal by soaps and detergents based on 1500 experiments. Acta Derm Venereol 1-183.

69. Monteiro-Riviere NA. 2010. Toxicology of the Skin. CRC Press.

70. Riethmuller C, McAleer MA, Koppes SA, Abdayem R, Franz J, Haftek M, Campbell LE, Maccallum SF, McLean WHI, Irvine AD, Kezic S. 2015. Filaggrin breakdown products determine corneocyte conformation in patients with atopic dermatitis. J Allergy Clin Immunol.

71. Feuillie C, Vitry P, McAleer MA, Kezic S, Irvine AD, Geoghegan JA, Dufrêne YF. 2018. Adhesion of Staphylococcus aureus to corneocytes from atopic dermatitis patients is controlled by natural moisturizing factor levels. MBio.

72. Kligman AM, Christophers E. 1963. Preparation of isolated sheets of human stratum corneum. Arch Dermatol 88:702-705.

73. Warner RR, Boissy YL, Lilly NA, Spears MJ, McKillop K, Marshall JL, Stone KJ. 1999. Water Disrupts Stratum Corneum Lipid Lamellae: Damage is Similar to Surfactants1. J Invest Dermatol 113:960-966.

74. Schaefer H, Rodelmeier TE. 1996. Principles of percutaneous absorption. Basel, Switz.

75. Anderson RL, Cassidy JM. 1973. Variations in Physical Dimensions and Chemical Composition of Human Stratum Corneum. J Invest Dermatol 61:30-32.

77. Lipsky ZW, German GK. 2019. Ultraviolet light degrades the mechanical and structural 
properties of human stratum corneum. J Mech Behav Biomed Mater 100.

690 78. Barnes TM, Greive KA. 2013. Use of bleach baths for the treatment of infected atopic

691 eczema. Australas J Dermatol.

692 79. Racioppi F, Daskaleros PA, Besbelli N, Borges A, Deraemaeker C, Magalini SI, Martinez sodium hypochlorite: Review of acute toxicology and poison control center experience. Food Chem Toxicol.

696

80. Fisher RG, Chain RL, Hair PS, Cunnion KM. 2008. Hypochlorite killing of communityassociated methicillin-resistant staphylococcus aureus. Pediatr Infect Dis J.

698 81. 2012. Characterization of the anisotropic mechanical properties of excised human skin. J Mech Behav Biomed Mater 5:139-148. 